\title{
Can habitat specialisation maintain a mosaic hybrid zone in marine bivalves?
}

\author{
Nicolas Bierne ${ }^{1, *}$, Patrice David ${ }^{2}$, Aimé Langlade ${ }^{3}$, François Bonhomme $^{1}$ \\ ${ }^{1}$ Laboratoire Génome, Populations, Interactions, CNRS UMR 5000, SMEL, 1 Quai de la Daurade, 34200 Sète, France \\ ${ }^{2}$ CEFE - CNRS, 1919 route de Mende, 34293 Montpellier Cedex 5, France \\ ${ }^{3}$ Laboratoire Conchylicole de Bretagne IFREMER, BP 26, 56470 La Trinité-sur-Mer, France
}

\begin{abstract}
Maintaining the integrity of differentiated genomes in marine organisms needs efficient isolation mechanisms, because planktonic larval dispersion provides contacts between taxa. Habitat specialisation is interesting in this respect, because it can both prevent interspecific crosses (each taxon reproduces in its own habitat) and eliminate hybrids (typically less fit than a parental taxon in each habitat). The contact zone between smooth-shelled mussels Mytilus edulis and M. galloprovincialis in Europe is a good example, as allozyme genotypes typical of both taxa seem to segregate into different habitats. However, allozymes may be selected directly and it is not known whether the same pattern can be extended to the whole genome. Here, we used 6 presumably neutral PCR markers to investigate habitat specialisation, focussing on the Bay of Quiberon, a small region in the midst of the contact zone between the 2 taxa. Confirming allozyme findings, our results indicate that habitat specialisation is apparent at the genomic scale, as $M$. edulis-like genotypes are found in sheltered or open-sea sites under freshwater influence, whereas M. galloprovincialis-like genotypes occupy exposed sites. Hybrid (or mixed) populations are found in open-sea or sheltered areas without freshwater influence. Therefore, habitat specialisation does contribute to the interspecific barrier. However, this mechanism seems insufficient to completely prevent the mixing of the 2 genomes, as mixed populations exist and provide opportunity for further hybridisation. Large gametic disequilibria within hybrid populations indicate the existence of restrictions to genetic exchange between the 2 taxa, even within a single habitat. Habitat-independent isolation mechanisms must, therefore, exist in addition.
\end{abstract}

KEY WORDS: Habitat specialisation · Hybrid zone · Introgression · Mytilus edulis · Mytilus galloprovincialis

\section{INTRODUCTION}

Habitat specialisation, i.e. the differential adaptation of genotypes to alternative ecological conditions, is a very appealing explanation for the speciation process (Bush 1975, Rice 1984, 1987). Indeed, selection rarely acts on reproductive isolation directly. Most of the time, it is assumed that disruptive selection acts epistatically on a set of loci and that selection only affects loci involved in pre-zygotic isolation via gametic disequi-

${ }^{*}$ Present address: Centre for the Study of Evolution and School of Biological Sciences, University of Sussex, Falmer, Brighton BN1 9QG, United Kingdom. Email: n-bierne@univ-montp2.fr librium (Dobzhansky 1940). This indirect path is probably the main obstacle to speciation by natural or sexual selection (Kirkpatrick \& Ravigné 2002). However, selection can operate directly or pleiotropically on a trait inducing reproductive isolation. An example of such a situation is observed when individuals are adapted to survive in a given habitat and tend to reproduce within the same habitat, i.e. with similarly adapted mates.

In the sea, habitat specialisation may appear as an especially important mechanism of reproductive isolation. Most marine organisms have the potential to migrate over long distances through a planktonic larval stage and populations are generally large. In such 
conditions, allopatric speciation would require sustainable effective geographic boundaries. The closing of the isthmus of Panama is an example of an effective boundary in the sea (Knowlton et al. 1993). However, such barriers are often hard to find (Palumbi 1992). Speciation in the sea may therefore require that reproductive isolating mechanisms evolve in the presence of a large amount of gene flow (parapatric or sympatric speciation). Palumbi (1994) has reviewed 4 mechanisms of pre-zygotic reproductive isolation in the sea: (1) behavioural mate preferences, although unlikely for sessile free-spawners; (2) preferential fertilisation; (3) spawning asynchrony; and (4) habitat specialisation. In the presence of gene flow, habitat specialisation driven by direct selection seems more powerful than the other 3 mechanisms that often require reinforcement (Kirkpatrick \& Ravigné 2002). In marine bivalves, habitat specialisation is likely to be driven by direct selection because adults are sessile and stay in the same habitat until reproduction. External fertilisation may occur between individuals adapted to the same habitat, since sperm dilution and adult densities may greatly limit long-distance fertilisation success in free-spawning invertebrates (review in Levitan 1998). Gamete dispersal is therefore believed to be effective at the scale of a few metres only (Levitan 1998) with the exception of very fine scale environmental variation, reproduction is thus expected to occur within habitats.

Examples of local adaptation in the marine literature include evidence for direct habitat-dependent selection at enzymatic loci (Koehn et al. 1980, Hilbish \& Koehn 1985, Lemaire et al. 2000, Schmidt et al. 2000, Schmidt \& Rand 2001). An interesting feature of these examples is that selection appears to be strong enough to produce detectable levels of local adaptation in adult populations despite large migration among habitats. The most famous case is probably the aminopeptidase allele frequency cline maintained between estuarine habitats of Long Island Sound and oceanic coastal zones in the mussel Mytilus edulis, despite extensive larval migration (Koehn et al. 1980).

Thus, environment-dependent selection might be strong enough to represent the first step toward speciation, triggering the evolution of reproductive isolation and ultimately, the divergence of the whole genome (including neutral loci) between the 2 newly created species. However, we are lacking clearly documented evidence for this in the marine environment.

Smooth-shelled mussels Mytilus spp. provide a unique opportunity to observe various stages of this process. They form a well-known species complex, with hybridisation over extensive areas such as the contact zone of $M$. edulis / $M$. galloprovincialis along the Western European coast. The main feature of this zone is its mosaic structure, in which populations of pure genotypes alternate with hybrid populations (Skibinski et al. 1983, Coustau et al. 1991, Daguin et al. 2001, Bierne et al. in press b). Allozyme surveys have revealed that spatial distributions of alleles at diagnostic loci (including an amino-peptidase) are correlated with environmental factors such as salinity (Skibinski 1983) or tidal height and wave exposure (Gosling \& Wilkins 1981, Gardner \& Skibinski 1988, Gosling \& McGrath 1990, reviewed in Gardner 1994). Within sympatric populations, alleles specific to $M$. galloprovincialis usually increase in frequency with size and age, due to differential viabilities between the juvenile and adult stages (Skibinski 1983, Gardner \& Skibinski 1988, Skibinski \& Roderick 1991, Gardner et al. 1993, Wilhelm \& Hilbish 1998, Hilbish et al. 2002). Differential susceptibility to wave action in exposed shores has been proposed as an explanation (Gardner \& Skibinski 1991, Willis \& Skibinski 1992).

However, other allozymes exhibited only slight differences, if any, between the 2 species (Skibinski et al. 1983). One may therefore suggest that the diagnostic allozymes are under direct selection, whereas other parts of the genome are not. In this case, neutral markers would cross the interspecific barrier, being only slightly slowed down by the indirect barrier effect of selection (Barton 1979, Barton \& Bengtsson 1986). Alternatively, all marker loci (be they diagnostic or not) may be neutral and indirectly affected by a strong genetic barrier due to selection on a sufficient number of other target loci. The variation among marker loci may reflect the fact that some loci happen to differentiate the 2 species, whereas others do not. This outcome could result from differences in the rate of allele sorting during divergence if it is compatible with demographic parameters (Avise 1994). Recently, noncoding introns (Daguin et al. 2001, Bierne et al. in press b) as well as mitochondrial DNA (Quesada et al. 1995, 1998, Rawson \& Hilbish 1998) have differentiated the 2 species at a large scale. This suggests that there has been sufficient time since divergence for independent coalescence of both nuclear and mitochondrial genes, and that the cohesion of the whole genomes (including neutral loci) is maintained at the level of the whole species. In the areas where both taxa coexist, habitat specialisation may be involved in species isolation if genotypes tend to segregate into different microhabitats. It is thus interesting to question at this scale the eventual role played by habitat selection in the maintenance of the integrity of genomes.

The Mytilus edulis / M. galloprovincialis contact zone may be best understood as a succession of several hybrid zones rather than a vast single hybrid zone. Hilbish et al. (2002) have recently described the genetic structure in SW Britain at a fine spatial resolution and have demonstrated a cline-like structure at the scale of 
100s of $\mathrm{km}$. Bierne et al. in press b have shown that 3 independent hybrid zones can be defined in France. In each of the 3 zones, differentiated source populations are involved. Depending on location, introgression processes appeared more or less advanced. In the central zone in south Brittany (France), hybridisation occurs between 2 differentiated patches ( $M$. edulis-like populations in the centre of the Bay of Biscay and M. galloprovincialis-like populations in NW Brittany). Patterns of introgression between these 2 patches appeared very complex. In the contact zone, a fine-scale mosaic was observed. Investigating fine-scale structure in this area thus appears very promising to evaluate the role of habitat specialisation in the maintenance of the hybrid zone. However, a precise analysis of hybridisation was

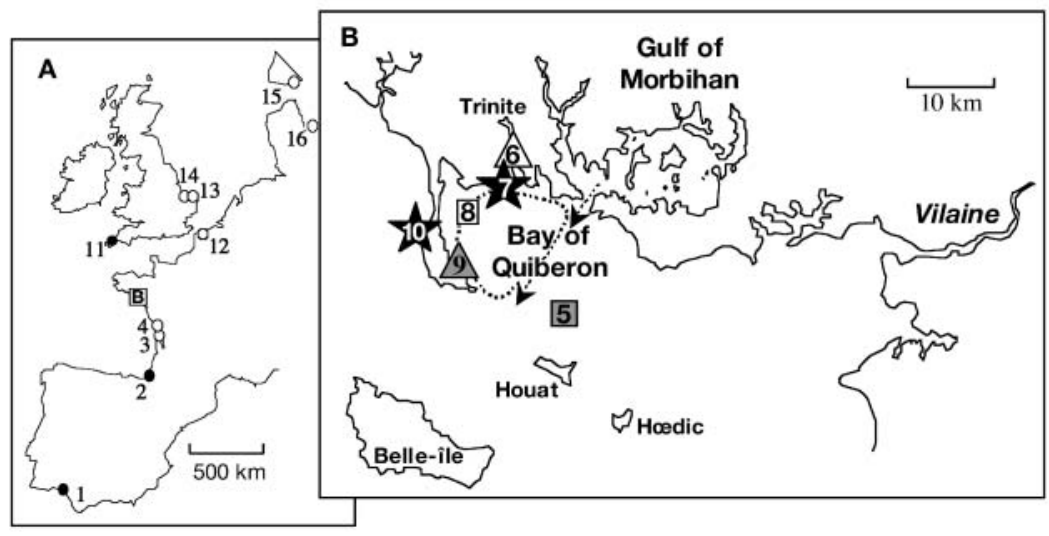

Fig. 1. Sampling localities for Mytilus spp. (A) Reference populations, (B) finescale sampling in the Bay of Quiberon. Stars: exposed sites; squares: open-sea areas; triangles: sheltered areas. Mostly M. galloprovincialis populations are in black, mostly $M$. edulis populations are open symbols and hybrid populations in grey. Dashed arrows represent currents during low tides (they are reversed during high tides). Samples names and samples sizes (in parentheses) are as follows: 1, Faro (67); 2, Biarritz (50); 3, Brouage (30); 4, Boyard (50); 5, Houataise (96); 6, Trinité sur Mer (96); 7, Pointe de Kerbihan (72); 8, Bay of Quiberon (66); 9, Port Haliguen (72); 10, Portivy (72); 11, Polzeath (49); 12, Grand Fort Philippe (50); 13, Tichwell (27); 14, Cley (32); 15, Flodevigen (53); 16, Gilleleje (35)

Table 1. Ecological characteristics of stations in the Bay of Quiberon area

\begin{tabular}{|c|c|c|c|c|}
\hline $\begin{array}{l}\text { Station number } \\
\text { and name }\end{array}$ & Wave action & $\begin{array}{l}\text { Salinity }^{\mathrm{a}} \\
\text { (\%о) }\end{array}$ & $\begin{array}{l}\text { Ecological } \\
\text { score }^{\mathrm{b}}\end{array}$ & $\begin{array}{l}\text { Mean } G \text { allele } \\
\text { frequency }\end{array}$ \\
\hline 05, Houataise & Open sea & $31-32$ & 1 & 0.42 \\
\hline 06, Trinité sur Mer & Sheltered & $29-30$ & 0 & 0.09 \\
\hline 07, Pointe de Kerbihan & Exposed & $29-30$ & 1 & 0.58 \\
\hline 08, Bay of Quiberon & Open sea & $30-31$ & 0 & 0.10 \\
\hline 09, Port Haliguen & Sheltered & $32-33$ & 1 & 0.36 \\
\hline 10, Portivy & Exposed & $32-33$ & 2 & 0.57 \\
\hline \multicolumn{5}{|c|}{ aLazure \& Salomon (1991) } \\
\hline \multicolumn{5}{|c|}{$\begin{array}{l}\text { both high salinity and exposition to wave action have been mentioned as } \\
\text { favourable to Mytilus galloprovincialis in previous studies. We have syn- } \\
\text { thesised both factors into a simple ecological score. } 0 \text { : non-exposed and } \\
\text { salinity below average }(\leq 31 \%) ; 1 \text { : non-exposed and salinity } \geq 31 \% \text { or } \\
\text { exposed and salinity } \leq 31 \% \text {; } 2 \text { : exposed and salinity } \geq 31 \% \text { o }\end{array}$} \\
\hline
\end{tabular}

hampered by the small number of loci used. In the prework, we have added 3 newly developed nDNA to the 3 previously described loci (Bierne et al. in pres b). Here, our aim was to focus on a small region in the middle of the contact zone in the Bay of Quiberon, in er to verify whether the habitat specialisation obcould be extended to non-coding parts of the zone. This information would allow us: (1) t that the separation between the 2 genomes is maintained at a very fine scale, as it is at a larger scale; (2) to test whether ecological factors such as wave exposure, salinity and/or correlated factors influence the spatial distribution of alleles at this scale; (3) to check whether these conclusions hold for a hybrid segment in southern Brittany, never analysed to date; and (4) to discuss whether segregation into different habitats is sufficient to prevent hybridisation and to evaluate the relative importance of the different factors involved in the barrier to gene flow.

\section{MATERIALS AND METHODS}

Collection of samples. Mytilus spp. samples of adult individuals $(>2 \mathrm{~cm}$, samples at random) were collected along the European Atlantic shores (Fig. 1). The 16 samples were numbered following their position along the coast from south to north. These are the same samples numbered $1,3,6$, $7,10,11,12,13,14,15,23,26,28,29$, 31 and 32 in Bierne et al. (in press b). Shell length of individuals from Samples 5 to 10 were measured (along the posterior-anterior axis) before molecular analyses. Because age is difficult to obtain in mussels, we used shell length as an indicator of both growth and survival, and thus, as a correlate of fitness.

Ecological characteristics of sites where Samples 5 to 10 were sampled (Fig. 1B) are known (Table 1). We have chosen 2 sheltered areas (Samples 6 and 9 represented by triangles in Fig. 1), 2 open sea areas on ropes hanging from buoys (Samples 5 and 8 represented by squares) and 2 exposed areas 
lacking protection from surf action (Samples 7 and 10 represented by stars). We have deliberately selected sites so that ecological parameters were not correlated with geographical distance. In this region, winds predominantly blow from the west. For this reason, the west side of the Quiberon peninsula (Sample $10)$ is called the 'wild coast'. The Quiberon peninsula thus offers a relative protection to the Bay of Quiberon. Currents and salinity of the Bay of Quiberon are described in Lazure \& Salomon (1991), and at a larger scale, in the Bay of Biscay, in Lazure \& Jegou (1998). The Gulf of Morbihan (see Fig. 1) acts as a reservoir that either empties or fills depending on the tide, thus creating a powerful current between its entry and the extremity of the Quiberon peninsula. The consequence is the generation of a gyre (Lazure \& Salomon 1991) that homogenises the whole Bay of Quiberon and that is also believed to act as a trap for plankton. Three samples (7, 8 and 9) are localised within this gyre. The influence of little rivers locally decreases salinity in the northern side of the Bay of Quiberon (Sample 8) and in the Trinité river (Samples 6 and 7) (Lazure \& Salomon 1991). Differences may sometimes reach 1 to $3 \%$. We have defined an ecological score that takes into account both wave action and salinity as described in Table 1.

Molecular markers. Three previously described length polymorphic DNA loci were used, 1 in the adhesive plaque protein gene, Glu-5' (Inoue et al. 1995, Rawson et al. 1996), and 2 introns, mac-1 (Ohresser et al. 1997, Daguin \& Borsa 1999, Daguin et al. 2001) and EFbis (Bierne et al. 2002).

We have designed 3 DNA markers by using the DALP technique (Desmarais et al. 1998). The first step of this technique generates a multi-banded pattern where presumptive length polymorphisms are located (Desmarais et al. 1998). Polymorphic bands are then eluted from dried gels and used as templates for a second round of PCR amplification. The resulting PCR products are sequenced directly. Sequences are used to design internal-specific primers with the aim of obtaining single co-dominant length polymorphism markers. The first step of the DALP has generated highly polymorphic multi-banded patterns in Mytilus spp. (see Fig. 3 in Desmarais et al. 1998). We have chosen 5 polymorphic band systems for sequencing. After sequencing, 3 band systems appeared to reveal length polymorphism. Primers designed to amplify single codominant markers are listed in Table 2. We used the
PCR and electrophoresis procedures described in Daguin \& Borsa (1999), except that the annealing temperature was adjusted for each locus (Table 1).

The DAMP1 locus exhibited two $10 \mathrm{bp}$ indels, one being almost diagnostic between Mytilus edulis and M. galloprovincialis, and the other being polymorphic within M. galloprovincialis. As a null allele was suspected within $M$. edulis, we had to design a second forward primer between the 2 indels (DAMP1-F2). As a consequence, the within-M. galloprovincialis polymorphism is absent with the DAMP1-F2/DAMP1-R primer set (Fig. 2). We have therefore read this locus as a bi-
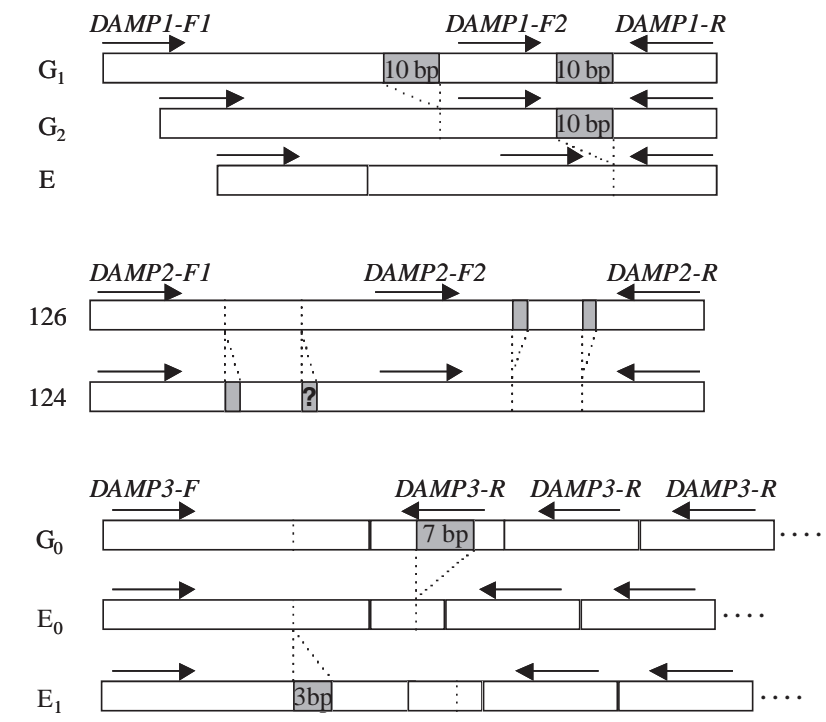

Fig. 2. Mytilus spp. Most important length polymorphisms for loci DAMP1 (GenBank \#480863-64), DAMP2 (GenBank \#480865-72) and DAMP3 (GenBank \#480873-74), and localisation of primers used 
allelic locus whatever the primers we used (pooling the 2 galloprovincialis alleles even when they could be distinguished).

The DAMP2 locus was first only partially diagnostic between Mytilus edulis and $M$. galloprovincialis. Moreover, a null allele was suspected within $M$. galloprovincialis. Sequences performed have revealed 3 single nucleotide indels localised in poly-(A/T) sequences; this locus is rich in such single nucleotide microsatellites (GenBank \#480865-72). We also designed a second forward primer, DAMP2-F2 (Fig. 2); with this primer, this locus exhibited a better diagnosticity that was attributed to a length polymorphism localised between the 2 forward primers (the question mark in Fig. 2) creating length homoplasy. We have observed 10 alleles; 2 frequent (124 and 126 bp long) and 8 rare ones $(114,122,123,125,127,129,134$ and 139). Five were characteristic of $M$. edulis $(114,123$, 124, 125 and 139) and 5 of M. galloprovincialis (122, $126,127,129$ and 134), according to their frequencies in reference samples and their first-axis co-ordinates based on a correspondence analysis (see below, Fig. 3).

One primer, DAMP3-R of the DAMP3 locus, is located on a minisatellite repeat (Fig. 2). Despite all our attempts, we were unable to sequence the other flanking sequence of this minisatellite. However, a $7 \mathrm{bp}$ indel, localised on the first repeat, appeared to be partially diagnostic between Mytilus edulis and M. galloprovincialis. With the primers we have used, we obtain a multi-banded pattern. The smaller band exhibits a presence/absence polymorphism and the second band exhibits the partially diagnostic length polymorphism that is repeated higher in the gel by other amplifications, which is enough to be read without ambiguity. A second indel of $3 \mathrm{bp}$ length was identified by sequencing (Fig. 2). Finally, DAMP3 exhibited 6 alleles; 4 were characteristic of $M$. edulis $\left(E_{0}\right.$ and $E_{1}$ in Fig. 2 , and 2 smaller, $E_{-1}$ and $E_{-2}$ ) and 2 were characteristic of $M$. galloprovincialis (the 2 bigger alleles with the amplification of the band due to the annealing on the first repeat).

Non-amplifying alleles (also called null alleles) are thought to be particularly frequent in marine bivalves because of their high genetic diversity (McGoldrick et al. 2000, Bierne et al. in press a). Hare et al. (1996) were the first to demonstrate the difficulty in designing primers without non-amplifying alleles within a single species in the American oyster Crassostrea virginica. The null allele problem at microsatellite loci in oysters has been reviewed by McGoldrick et al. (2000). In the present case, the fact that primers have to probe in 2 different species makes things potentially worse as the probability to find the $\sim 50 \mathrm{pb}$ (a PCR primer pair) of contiguous monomorphic sites necessary to design primers, is even lower than at the intra-specific level.
In addition, the Hardy-Weinberg and linkage disequilibria analysis required in a hybrid zone study, needs that null alleles be removed. Several technical procedures may limit the impact of null alleles (Bierne et al. in press a). One of these procedures was to design a second set of primers for DAMP1 and DAMP2 (see above). Another was to decrease the PCR annealing temperature as much as we could before amplifying secondary parasitic bands due to non-specific priming (see Table 2). This procedure allows possible mismatches to occur at the targeted priming sites. Finally, the good performance of the 6 markers we used was validated by Hardy-Weinberg and linkage equilibrium (HWLE) within reference samples, and also by the good concordance among loci within the hybrid zone (see below).

Data analyses. Genetic differentiation was studied by correspondence analysis (CA) on the matrix of allele counts per sample using the GENETIX software (Belkhir et al. 1996). CA is particularly well suited to describe the genetic structure in hybrid zones. Homogeneity of genotypic frequencies between pairs of populations was tested by an exact test using the GENEPOP software (Raymond \& Rousset 1995) which allowed us to group samples with the same genetic composition.

The reproductive barrier between 2 differentiated gene pools can be studied by evaluating the extent to which alleles typical of both gene pools coexist within the same individuals. Two types of disequilibrium are relevant to this evaluation: (1) Hardy-Weinberg disequilibrium indicates the deviations from random mating among the 2 gene pools; and (2) linkage disequilibrium (i.e. gametic disequilibria) reveals the limitations for recombination between the 2 corresponding genomes. Pairwise associations within loci, $\kappa_{1,1}$ (corresponding to an averaged Hardy-Weinberg disequilibrium) and between loci within genomes, $\kappa_{0,2}$ (corresponding to an averaged pairwise gametic disequilibrium) were estimated following the method described in Barton (2000), using MATHEMATICA 3.0 (Wolfram 1996) add-ons provided by N. Barton (http://helios. bto.ed.ac.uk/evolgen/). The advantage of this method is that both linkage and Hardy-Weinberg disequilibria are estimated jointly. Because Barton's method (as well as the hybrid zone framework in general) only considers disequilibria between pairs of alleles typical of either species, within-species diversity is not relevant to this method. Alleles were therefore pooled, within each locus, into species-specific compound alleles according to their co-ordinates on CA Axis 1, as described in Daguin et al. (2001). Synthetic alleles characteristic of Mytilus galloprovincialis populations were called $G$ and synthetic alleles characteristic of $M$. edulis populations were called $E$. In addition to Hardy-Weinberg and link- 


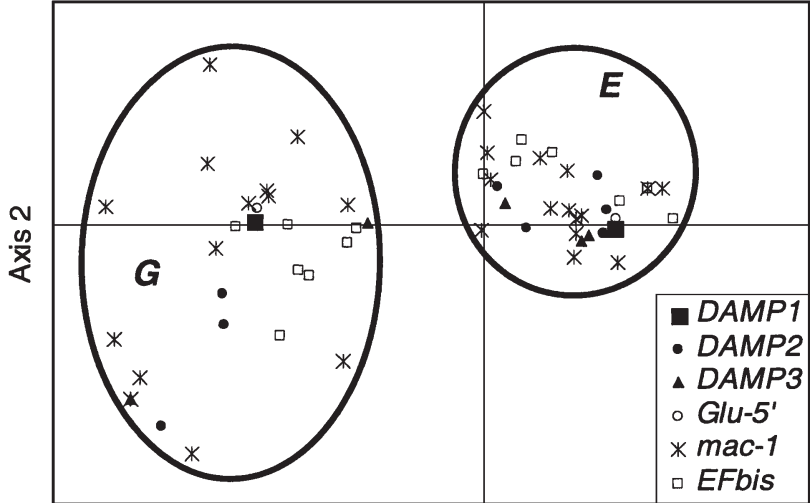

Axis 1

Fig. 3. Mytilus edulis (E) and M. galloprovincialis $(G)$. Projection of alleles on the first factorial plane of correspondence analysis (CA; Benzécri 1982)

age disequilibrium analysis by Barton's method, synthetic alleles were also used: (1) to calculate a simple hybrid index that is the number of $G$ alleles per individual; and (2) to present a simplification of the genetic structure with synthetic allele frequencies (although the full variation is taken into account in the CA).

As mentioned in the 'Introduction', genotype/phenotype (shell length) associations can potentially reveal the action of selection at the adult stage favouring one mussel type over the other (say, Mytilus galloprovincialis over $M$. edulis). These associations were investigated in several ways. Differences in shell length between classes of single-locus or multi-locus hybrid indices were tested using 1-way ANOVAs with fixed effect. Individuals from hybrid samples (where significant departure from Hardy-Weinberg and linkage equilibrium were found) were also classified as M. edulis-like and M. galloprovincialis-like individuals using the assignation software Partition (Dawson \& Belkhir 2001). Finally, each sample was sorted by size and grouped into size quartiles, ranging from the smallest (Quartile I) to the largest (Quartile IV). G allele frequencies (locus by locus or the average on all the loci) were plotted on size quartiles and the relationship between the 2 parameters was expressed as product-moment correlations.

\section{RESULTS}

\section{Genetic variability}

Allele frequencies are presented in Appendix 1. Fig. 3 presents the projection of alleles and Fig. 4 the projection of samples on the first factorial plane. CA Axis 1 reflects the allele frequency gradient between

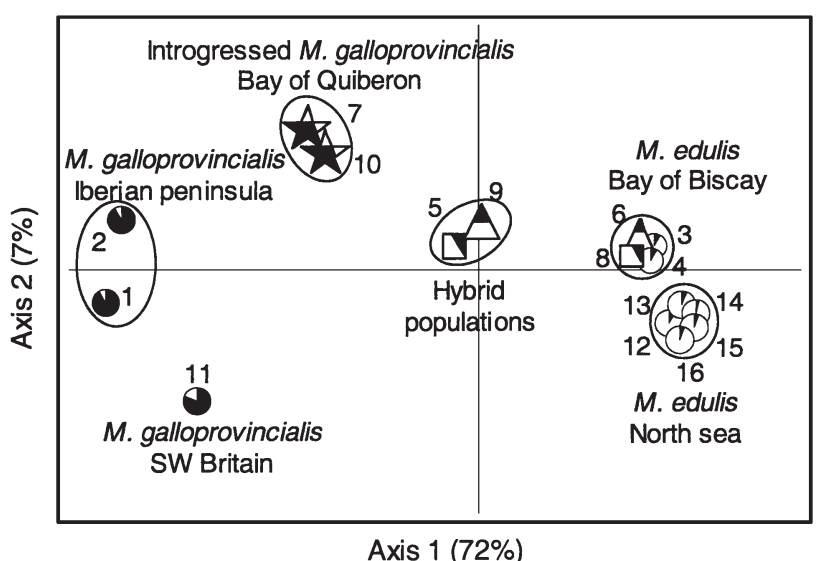

Fig. 4. Mytilus spp. Projection on the first factorial plane of correspondence analysis (CA; Benzécri 1982) of samples centres of gravity. Stars: exposed sites; squares: open-sea areas; triangles: sheltered areas; circles: reference populations. Station locations can be found in Fig. 1

the 2 species, from Mytilus galloprovincialis on the left to $M$. edulis on the right. The frequencies of the synthetic $G$ allele at each locus in each sample are presented in Fig. 5. The average $G$ frequency over the 6 loci is also presented as black sectors in the pie diagrams in Fig. 4. Ellipses in Fig. 4, group samples for which the homogeneity of genotypic frequencies cannot be rejected (Appendix 2). Within-species genetic structures appear on Axis 2, between M. edulis of the North Sea and M. edulis of the Bay of Biscay on one hand, and between M. galloprovincalis of the Iberian peninsula and M. galloprovincalis of Brittany and SW England on the other. The problem of intraspecific variation along the Atlantic coast has been treated at length in a previous paper (Bierne et al. in press b), and the present 6 locus analysis cannot bring more to this issue since the 3 added loci are virtually monomorphic

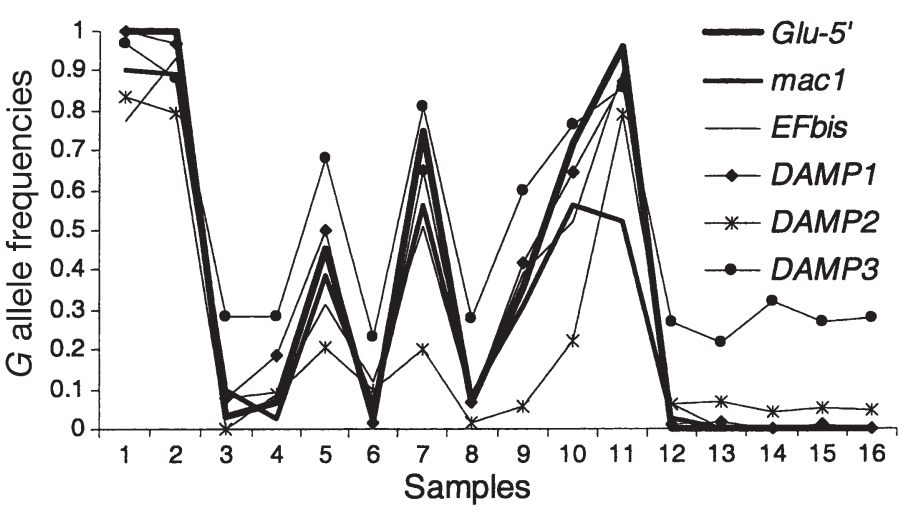

Fig. 5. Mytilus spp. $G$ allele frequencies for the 16 samples. Station locations can be found in Fig. 1 
within each species (when more than 2 alleles are found, all but 1 are rare). Here, we focus on the between-species differentiation. A strong introgression from $M$. edulis towards $M$. galloprovincialis occurs at locus DAMP2 in south Brittany (Fig. 5).

\section{Correlation with environmental factors}

The fine-scale mosaic structure in the Bay of Quiberon is evident (Figs. 1 \& 5). The association between the genetic composition of samples and wave exposure previously described with allozymes (review in Gardner 1994) is also found in the present study. A significant correlation is found between the mean $G$ allele frequency of a sample and the ecological score of the site (Kendall rank test, $r=0.7, p=0.048$ ). The 2 exposed areas ( 7 and 10) are the most rich in Mytilus galloprovincialis alleles, and open-sea and sheltered areas are either grouped with Bay of Biscay $M$. edulis (6 and 8) or intermediate (5 and 9) (Fig. 4, Table 1), the 2 most $M$. edulis samples (6 and 8) being in sites where the salinity is slightly decreased. Mosaicism is well known in this hybrid zone (Skibinski et al. 1983, Coustau et al. 1991, Daguin et al. 2001, Bierne et al. in press b); however, the relationship between environmental conditions and such drastic changes in allele frequencies at a very small scale has seldom been noticed.

\section{Analysis of disequilibria}

Hardy-Weinberg and linkage disequilibria depend on the level of differentiation between parental populations that are the source of hybridisation (Barton 2000). The more introgressed source populations are, the slighter the disequilibria (Barton 2000). This can be measured by the difference in allele frequency between source populations, $\Delta p$ (Barton 2000). If all the loci are similarly introgressed (same $\Delta p$ ), then they share the same information. However, different loci may have reached different levels of introgression (different $\Delta \mathrm{p}$ ) because of the genomic architecture of the barrier to gene flow (sensu Rieseberg 1999). In our case, if all the 6 loci are roughly as strongly differentiated between Mytilus galloprovincialis populations of the Iberian Peninsula and $M$. edulis populations of the North Sea $(D A M P 1, \Delta \mathrm{p}=0.98 ; D A M P 2, \Delta \mathrm{p}=0.76$; $D A M P 3, \Delta \mathrm{p}=0.66 ;$ Glu-5', $\Delta \mathrm{p}=1 ;$ mac-1, $\Delta \mathrm{p}=0.9$; EFbis, $\Delta \mathrm{p}=0.84)$, a strong discrepancy is observed between locus DAMP2 $(\Delta \mathrm{p}=0.15)$ and other loci $(\Delta \mathrm{p}>$ $0.4)$ when considering introgressed $M$. galloprovincialis populations of Brittany and introgressed $M$. edulis populations of the Bay of Biscay as source populations $(D A M P 1, \Delta \mathrm{p}=0.61 ; D A M P 2, \Delta \mathrm{p}=0.15$,
$D A M P 3, \Delta \mathrm{p}=0.53 ;$ Glu-5', $\mathrm{p}=0.69 ;$ mac-1, $\Delta \mathrm{p}=0.49$; EFbis, $\Delta \mathrm{p}=0.42$ ). Because of this strong introgression at locus DAMP2 in south Brittany, this locus is not informative in this area, and therefore we have simply removed it from the Hardy-Weinberg and linkage disequilibria analysis. Pairwise associations within loci, $\kappa_{1,1}$, and between loci, $\kappa_{0,2}$, have been estimated after pooling samples that did not show significant differences in genotypic frequencies and are presented in Fig. 6 with the hybrid index distribution. Hardy-Weinberg and linkage equilibrium was rejected in 2 cases: (1) in Bay of Quiberon hybrid populations (Samples 5 and 9, Fig. 6) where the hybrid index distribution is bimodal; and (2) in Sample 11 from Polzeath in SW Britain (Fig. 6). Samples from exposed areas of the Bay of Quiberon exhibited slight but non-significant associations (Fig. 6).

\section{Genotype/shell length associations}

Among all the tests we have performed to detect a genotype/shell length association, none was significant at the $5 \%$ level (data not shown). We were unable to detect a trend for one genotype to be larger than another. Neither did we detect the classical trend for Mytilus galloprovincialis alleles to increase in frequency with shell length (review in Gardner 1994), even with locus Glu-5' for which this association was noticed elsewhere (Rawson et al. 1998, Wilhelm \& Hilbish 1998).

\section{DISCUSSION}

Correlations between the spatial distribution of alleles at allozymes and wave exposure and/or salinity are a well-known observation in the Mytilus edulis / $M$. galloprovincialis hybrid zone (review in Gardner 1994). Here, we extend the analysis of habitat specialisation and fine-scale mosaic structure to non-coding DNA variants, which show the same trend. This similarity has interesting implications about (1) the strength of the barrier to neutral gene flow between the 2 species; (2) the importance of habitat specialisation compared with other mechanisms of reproductive isolation; and (3) the importance of habitat specialisation on the large-scale maintenance of the zone.

\section{How strong is the interspecific genetic barrier in Brittany?}

Allozyme studies on the Mytilus edulis /M. galloprovincialis hybrid zone in France have concluded that 

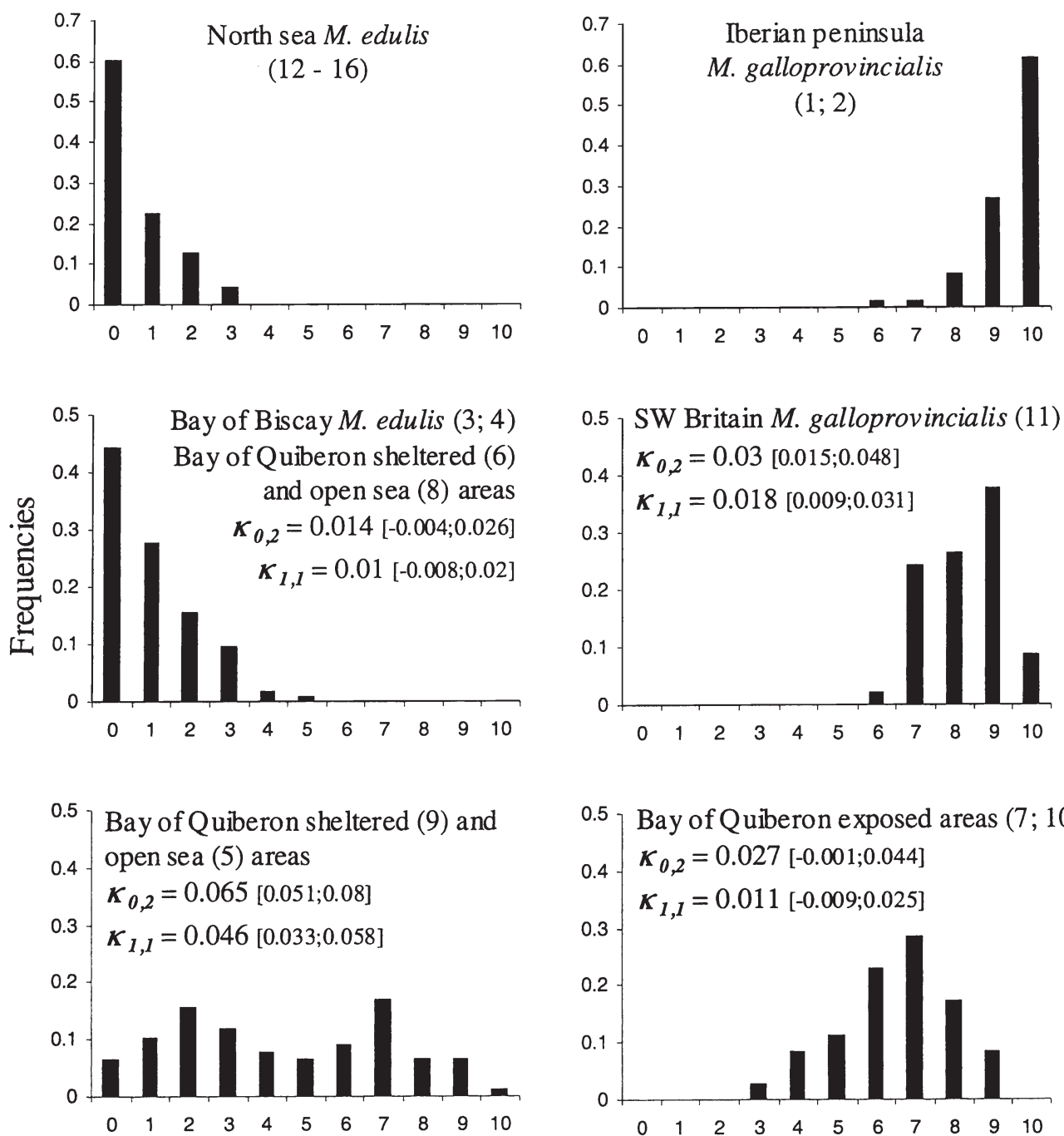

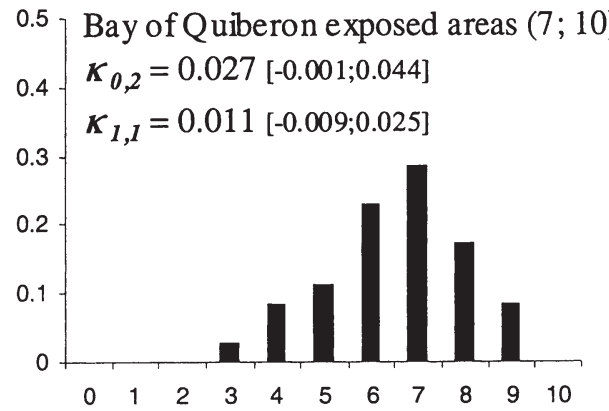

Hybrid index
Fig. 6. Mytilus spp. Hybrid index distribution and pairwise associations within loci, $\kappa_{1,1}$, 95\% CI (corresponding to an average Hardy-Weinberg disequilibrium) and between loci within genomes, $\kappa_{0,2}, 95 \% \mathrm{CI}$ (corresponding to an average pairwise gametic disequilibrium) estimated following Barton's method (2000) extensive hybridisation occurs in Brittany, because no departure from the Hardy-Weinberg equilibrium occurred in a sample of intermediate populations from this area (Coustau et al. 1991, Viard et al. 1994). However, if hybridisation is easy, it is a paradox that strong differentiation is maintained among populations despite a potential for extensive larval dispersal. On the other hand, if the factors separating the 2 species are environmental (exogenous), geographical variation of these factors may produce geographical variation in the strength of the barrier to gene flow. Following this line, one may suggest that the barrier to gene flow is partially removed in Brittany. In this case, the large-scale persistence of 2 incompletely blended entities ( $M$. edulis in the North Sea and M. galloprovincialis near the Iberian Peninsula) would rely on active barriers localised elsewhere (in SW Britain for example, where high departure from HWLE are found; Skibinski et al. 1983).
In Bierne et al. (in press b), we argue against this latter view. A detailed sampling revealed very high departures from HWLE in some populations in south Brittany (Daguin et al. 2001, Bierne et al. in press b). Allele frequencies of these samples were intermediate between those of Bay of Biscay Mytilus edulis and of M. galloprovincialis-like samples at HWLE. However, the latter were not identical to Iberian populations, as they had actually integrated neutral alleles from local $M$. edulis at some marker loci. Our conclusion was that these partially introgressed M. galloprovincialis, instead of pure populations, locally served as source populations for hybridisation. The barrier (demonstrated by departures from HWLE) is underestimated when Iberian $M$. galloprovincialis are used as reference populations (as is usually done) instead of local M. galloprovincialis. It is essential to bear this difference in mind in order to analyse fine-scale population structure. 
In the Bay of Quiberon area, 3 kinds of samples are observed (Figs. 4 \& 5): 2 Mytilus edulis-like samples (6 and 8) at HWLE that group with Bay of Biscay $M$. edulis populations (3 and 4); 2 M. galloprovincialis-like samples ( 7 and 10) that are strongly introgressed by $M$. edulis alleles but do not significantly depart from HWLE; and 2 hybrid samples (5 and 9), intermediate between the 2 previous groups (Fig. 4) and showing strong departures from HWLE as well as a bimodal distribution of the hybrid index (Fig. 6). The theoretical maximum gametic disequilibrium, obtained under a scenario of simple admixture (Barton 2000) of local $M$. edulis and $M$. galloprovincialis is: $\kappa_{0,2 \max }=0.062$. This value is approximately that estimated in these hybrid samples. Thus, the barrier between the 2 local $M$. edulis-like and M. galloprovincialis-like genomes seems strong in this area. Note that, if Iberian populations had been taken as $M$. galloprovincialis references, Populations 7 and 10 would have been classified as hybrid populations and apparent HWLE in these populations taken as evidence for a lack of barrier (in contradiction with Samples 5 and 9).

Moreover, drastic changes in allele frequencies are observed at a very fine scale. Taking into account the huge potential for dispersal of mussels, patches of very differentiated Mytilus edulis-like and M. galloprovincialis-like populations at neutral markers could not be maintained at such a small distance as a few $100 \mathrm{~m}$ (between Samples 6 and 7) without very strong reproductive isolation (be it pre- or post-zygotic). Currents are also believed to homogenise the Bay of Quiberon (Lazure \& Salomon 1991), further reinforcing the efficiency of larval migration.

The similar results obtained here with presumably neutral markers and elsewhere with allozymes (review in Gardner 1994) strongly suggest that none of the markers used to date is directly involved in the reproductive isolation between Mytilus edulis and M. galloprovincialis. They are more likely simply neutral markers slowed down by the barrier to gene flow generated by other genes elsewhere in the genome. The discrepancy in the level of introgression among loci is therefore easily explained by the genomic architecture of the barrier to gene flow, i.e. the number of isolation genes and their distribution throughout the genome (Rieseberg 1999). This conclusion contrasts with the recent claim of direct selection on allozymes in an other mussel hybrid zone; between $M$. edulis and $M$. trossulus in the transition between the North Sea and the Baltic Sea (Riginos et al. 2002).

Finally, for such an interspecific genetic barrier to neutral gene flow to be so strong, hybridisation must be rare. This conclusion poses the problem of the relative importance of the different factors, especially habitat specialisation, involved in the barrier.

\section{Does habitat specialisation alone explain the barrier to gene flow?}

Genetic structure at a fine scale within the Bay of Quiberon does seem to correlate with environmental factors. As mentioned above, previous studies suggested that Mytilus galloprovincialis and M. edulis are specialised within the contact zone in exposed and sheltered habitats, respectively (Gosling \& Wilkins 1981, Gardner \& Skibinski 1988, Gosling \& McGrath 1990, Gardner 1994). However, this relationship was based on allozyme studies. Direct habitat-dependent selection on allozymes cannot be excluded and it was therefore difficult to know whether habitat specialisation locally affected the complete genomes. Indeed, there exist some conditions in which theoretical models predict allele frequencies to differ among microhabitats only at loci directly responsible for habitat specialisation, whereas they show little or no differentiation among habitats at other diagnostic loci under endogenous selection (Kruuk 1997). Our results confirm that presumably neutral molecular markers behave as allozymes, as $M$. galloprovincialis-like allele frequencies are mostly found in exposed sites ( 7 and 10), whereas $M$. edulis-like and intermediate allele frequencies are found in open sea or sheltered areas $(5,6,8$ and 9). A possible influence of salinity can also be suspected because hybrid populations (5 and 9) occur in sites where the surface salinity is higher than M. edulis populations (6 and 8), both under freshwater influences (Lazure \& Salomon 1991). The fact that neutral markers and allozymes produce similar results is in agreement with the hypothesis that genomes are at least partly 'congealed' (sensu Turner 1967, Kruuk et al. 1999), or in other words, that genomes roughly behave as a single pleiotropic locus, supported by the observation of strong barriers to hybridisation in this area (see above).

However, there are 2 reasons why habitat specialisation alone is not sufficient to explain the strength of the barrier to gene flow. The first argument comes from the genotypic composition of hybrid populations (5 and 9). Separating 2 genomes just with habitat specialisation requires strong specialisation where specialised genotypes rarely, if ever, recruit in the wrong habitat (Rice 1987, Kruuk 1997). The mere existence of sites where the 2 genomes are present, roughly at the same frequencies, shows that some habitats provide important opportunities of contacts between the Mytilus edulis and M. galloprovincialis genomes. Such populations would represent 'bridges' between specialised genomes if habitat specialisation were the only cause of the barrier. However, strong departures from HWLE are maintained within these populations (see above) and therefore, interspecific crosses are limited, even 
when both species occur in the same habitat, by some other factor. This restriction could be pre-zygotic isolation within habitats (assortative fertilisation or spawning asynchrony) and/or selection against hybrids irrespective of the habitat. Both hypotheses have received experimental support (for asynchronous spawning see Seed 1971, Gardner \& Skibinski 1990, Secor et al. 2001; for low survival of hybrid larvae see Beaumont et al. 1993, Bierne et al. 2002; and for assortative fertilisation see Bierne et al. 2002).

The second argument is related to habitat specialisation by post-settlement selection. According to standard theory (e.g. Slatkin 1973), post-settlement selection alone would have to be extremely strong to maintain small-scale differentiation. In other words, exposed areas should be almost lethal for Mytilus edulis and sheltered areas almost lethal for M. galloprovincialis. This theory holds for a locus directly under selection, and a higher selection coefficient and/or tight linkage would be needed to predict habitat segregation at neutral marker loci (Barton \& Bengtsson 1986). We were unable to find any indirect manifestation of selection via hybrid index/shell length associations in our samples. Previous studies that have attempted to estimate environment-dependent selection coefficients found: (1) a systematic advantage for M. galloprovincialis genotypes, even in habitats dominated by M. edulis (Gosling \& McGrath 1990, Gardner 1994); and (2) an apparently too small viability differential (Gardner 1994) to allow the maintenance of separated genomes by this single mechanism. Alternatively, specialisation may involve some active habitat preference acting before recruitment (Gosling \& McGrath 1990). Contrary to viability selection, habitat choice does not result in as great a load and may be an interesting subject for future investigation.

The results presented here are finally very similar to those obtained on another well-documented marine hybrid zone between the hard clams Mercenaria mercenaria and M. campechiensis in the Indian River lagoon in Florida (Arnold et al. 1991, 1996, Bert \& Arnold 1995, reviewed in Hilbish 2001). The hard clams hybrid zone is maintained both by exogenous directional selection and endogenous selection against hybrids. However, habitat specialisation alone would probably not have been sufficient to prevent neutral gene flow if selection against hybrids were not also involved.

\section{Introgression heterogeneity among the genome}

Large-scale patterns of introgression have been described at 3 loci (Glu-5', mac-1 and EFbis) in a previous paper (Bierne et al. in press b). In Brittany, introgression appeared mostly asymmetrical from Mytilus edulis towards $M$. galloprovincialis. This is confirmed here with 3 more loci (Fig. 5). However, for the DAMP2 locus, this introgression is exceptionally strong. On the other hand, at a large scale, this locus strongly differentiates between Iberian $M$. galloprovincialis and North Sea $M$. edulis, and a $G$ allele frequency as high as Iberian populations is restored in SW Britain. Local differences among loci may arise from the genomic architecture of the barrier (the effect of physical linkage, and the physical proximity of the marker loci to selected loci). Another possibility is that, depending on their position on the chromosome, different markers are indirectly affected by different forms of selection, i.e. habitat specialisation, pre-zygotic isolation or hybrid depression. The barrier could then be relaxed at the scale of habitat variation for some parts of the genome where habitat specialisation genes are absent, but active at a larger scale for the whole genome. These hypotheses correspond to situations where gametic disequilibria are locally broken to allow different genes to behave independently (Kruuk 1997).

\section{Spatial scale of the components of the interspecific barrier}

The Mytilus edulis / M. galloprovincialis hybrid zone extends over a considerable distance, from the SW of France to Scottish coasts (Skibinski et al. 1983, Coustau 1991). Instead of a single genetic gradient from $M$. galloprovincialis of the Iberian Peninsula to $M$. edulis populations in the North Sea, several successive transitions are observed delineating patches of populations characterised by high frequencies of parental alleles.

Patches of $M$. galloprovincialis-like populations are found in Brittany, SW Britain, Ireland and Scotland. Transitions between patches are not often clinal but repeatedly form fine-scale mosaics which are correlated with habitats as observed in the present study. The geographic structure of the hybrid zone should therefore more accurately be termed a 2-scale mosaic structure. Can we reconcile the fine- and large-scale structures into a single framework?

Several authors have suggested that ecological factors explaining micro-geographic variation are also responsible for the macro-geographic variation (Gosling \& Wilkins 1981, Skibinski 1983, Gardner \& Skibinski 1988, Gardner 1994). Identification of environmental factors that can explain the distribution of the 2 species both at a large and at a small scale would support this hypothesis. The salinity map of Lazure \& Jegou (1998) reveals that the large Mytilus edulis patch in the Bay of Biscay roughly coincides with a zone of low salinity due to the influences of the Gironde and Loire plumes. This interaction echoes the 
differences between more or less saline microhabitats suggested at a small scale within the Bay of Quiberon (this study), situated on the northern edge of the patch. On the other hand, microhabitat differentiation between sheltered and exposed habitats cannot be involved at a large scale, as both habitat types exist throughout the European Atlantic coasts. Temperature is certainly unable to explain fine-scale genetic structures, although it has often been invoked to explain the northern and southern limits of the contact zone between the 2 mussel species (Skibinski et al. 1983, Gardner 1994, Hilbish et al. 1994). However, we currently have no convincing evidence of any direct implication of temperature, especially when one considers that M. galloprovincialis are found as far north as Scotland (Skibinski et al. 1983) and M. edulis as far south as the Bay of Biscay.

We propose that an alternative explanation could be found in the multiplicity of factors responsible for the barrier to gene flow and in stochastic migration events during secondary contact. The contact zone may have been stabilised in its current position (if it actually proves to be stable) because of a strong barrier to gene flow, while the position itself reflects past migrational stochasticity which occurred early in the secondary contact, rather than adaptation to specific environments. The barrier may be due to the cumulating effect of pre-zygotic isolation and reduced hybrid fitness all along the zone of contact. Habitat specialisation at a small scale can be considered as 1 mechanism (among others) involved in both types of isolation, although not in the large-scale repartition of the 2 species. In this context, environmental variation may explain the localisation of transition zones (where habitat specialisation is often observed) but not necessary the localisation of patches of pure species (where the correlation between genetical and environmental variations seems to be erased). Transition zones may also be stabilised in areas where dispersal is reduced (Barton 1979), as in the SW of France where a local reduction in population density linked to a diminution of hard substrates along sandy beaches may reduce gene flow. The concomitant effect of different factors that act at different scales and the dispersal characteristics of mussels shape this unique hybrid zone with a complexity rarely found in the terrestrial realm.

Appendix 1. Allelic frequencies at the DAMP1, DAMP2,DAMP3, Glu-5', mac-1 and EFbis loci. -, allele absent in sample; $n$, sample size. See Fig. 1 for sample names and locations

\begin{tabular}{|c|c|c|c|c|c|c|c|c|c|c|c|c|c|c|c|c|}
\hline (n): & $\begin{array}{c}1 \\
\text { FAR } \\
(67)\end{array}$ & $\begin{array}{c}2 \\
\text { BTZ } \\
(50)\end{array}$ & $\begin{array}{c}3 \\
\text { BRO } \\
(30)\end{array}$ & $\begin{array}{c}4 \\
\text { BOY } \\
(60)\end{array}$ & $\begin{array}{c}5 \\
\text { HOU } \\
(96)\end{array}$ & $\begin{array}{c}6 \\
\text { TRI } \\
(96)\end{array}$ & $\begin{array}{c}7 \\
\text { PK } \\
(72)\end{array}$ & $\begin{array}{c}8 \\
\mathrm{BQ} \\
(66)\end{array}$ & $\begin{array}{c}9 \\
\mathrm{PH} \\
(72)\end{array}$ & $\begin{array}{c}10 \\
\text { PORT } \\
(72)\end{array}$ & $\begin{array}{c}11 \\
\text { POL } \\
(49)\end{array}$ & $\begin{array}{c}12 \\
\text { GFP } \\
(50)\end{array}$ & $\begin{array}{c}13 \\
\text { TICH } \\
(27)\end{array}$ & $\begin{array}{c}14 \\
\text { CLEY } \\
(32)\end{array}$ & $\begin{array}{c}15 \\
\text { FLO } \\
\text { (53) }\end{array}$ & $\begin{array}{c}16 \\
\text { GIL } \\
(35)\end{array}$ \\
\hline \multicolumn{17}{|l|}{ DAMP1 } \\
\hline & - & 0.03 & 0.92 & 0.82 & 0.5 & 0.99 & 0.35 & 0.93 & 0.58 & 0.36 & 0.13 & 0.99 & 1 & 0.98 & 0.99 & 1 \\
\hline$G$ & 1 & 0.97 & 0.08 & 0.18 & 0.5 & 0.01 & 0.65 & 0.07 & 0.42 & 0.64 & 0.87 & 0.01 & - & 0.02 & 0.01 & - \\
\hline \multicolumn{17}{|l|}{ DAMP2 } \\
\hline 114 & - & - & - & 0.01 & - & 0.01 & - & - & 0.01 & - & - & - & - & - & - & - \\
\hline 122 & - & 0.01 & - & - & - & - & - & - & - & - & 0.01 & - & - & - & - & - \\
\hline 123 & - & - & - & - & 0.02 & 0.01 & - & - & - & - & - & - & - & - & - & - \\
\hline 124 & 0.17 & 0.2 & 0.96 & 0.89 & 0.74 & 0.87 & 0.8 & 0.94 & 0.93 & 0.78 & 0.21 & 0.93 & 0.96 & 0.92 & 0.94 & 0.95 \\
\hline 125 & 0.02 & 0.03 & - & 0.09 & 0.08 & 0.06 & 0.09 & - & 0.01 & 0.11 & 0.03 & 0.03 & 0.02 & 0.03 & 0.03 & 0.02 \\
\hline 126 & 0.79 & 0.73 & - & - & 0.12 & 0.03 & 0.09 & 0.02 & 0.05 & 0.1 & 0.72 & 0.03 & 0.02 & 0.03 & 0.02 & 0.03 \\
\hline 127 & - & 0.01 & - & - & - & - & - & - & - & 0.01 & 0.01 & - & - & - & - & - \\
\hline 129 & - & 0.01 & - & - & - & - & 0.01 & - & - & - & 0.01 & - & - & - & - & - \\
\hline 134 & 0.02 & 0.01 & - & - & 0.01 & - & 0.01 & - & - & - & 0.01 & - & - & - & - & - \\
\hline 139 & - & - & 0.04 & 0.01 & 0.03 & 0.02 & 0 & 0.04 & - & - & - & 0.01 & - & 0.02 & 0.01 & - \\
\hline \multicolumn{17}{|l|}{ DAMP3 } \\
\hline$E_{-2}$ & 0.01 & 0.01 & 0.05 & - & 0.01 & - & - & 0.05 & - & 0.04 & 0.01 & 0.01 & - & 0.02 & 0.01 & - \\
\hline$E_{-1}$ & - & 0.01 & 0.02 & 0.02 & 0.01 & 0.01 & - & 0.02 & 0.01 & - & - & - & 0.02 & 0 & 0.01 & 0.02 \\
\hline$E_{0}$ & - & 0.06 & 0.62 & 0.6 & 0.28 & 0.7 & 0.17 & 0.62 & 0.36 & 0.18 & 0.11 & 0.64 & 0.64 & 0.63 & 0.62 & 0.64 \\
\hline$E_{1}$ & 0.02 & 0.04 & 0.03 & 0.1 & 0.03 & 0.06 & 0.02 & 0.04 & 0.03 & 0.02 & 0.02 & 0.08 & 0.02 & 0.14 & 0.09 & 0.07 \\
\hline$G_{0}$ & 0.97 & 0.87 & 0.28 & 0.28 & 0.67 & 0.23 & 0.81 & 0.27 & 0.6 & 0.76 & 0.86 & 0.27 & 0.32 & 0.21 & 0.27 & 0.27 \\
\hline$G_{1}$ & - & 0.01 & - & - & - & - & - & - & - & - & - & - & - & - & - & - \\
\hline \multicolumn{17}{|l|}{ Glu-5' } \\
\hline$G$ & 1 & 1 & 0.03 & 0.07 & 0.45 & 0.03 & 0.75 & 0.07 & 0.35 & 0.72 & 0.96 & - & - & - & - & - \\
\hline$E$ & - & - & 0.97 & 0.93 & 0.55 & 0.97 & 0.25 & 0.93 & 0.65 & 0.28 & 0.04 & 1 & 1 & 1 & 1 & 1 \\
\hline \multicolumn{17}{|l|}{ mac-1 } \\
\hline f1 & - & 0.01 & - & - & - & - & - & - & - & - & - & - & - & - & - & - \\
\hline$f 2$ & - & 0.01 & - & - & - & - & - & - & - & - & - & - & - & - & - & - \\
\hline b1 & 0.16 & 0.1 & 0.02 & - & 0.06 & - & 0.04 & 0.01 & 0.03 & 0.08 & 0.06 & 0.01 & - & - & - & - \\
\hline$b 2$ & - & 0.02 & - & - & - & - & - & - & - & - & 0.02 & - & - & - & - & - \\
\hline b3 & - & - & 0.02 & - & - & - & - & - & - & - & 0.02 & - & - & - & - & - \\
\hline$b 4$ & - & - & - & - & - & - & - & - & - & 0.01 & - & - & - & - & - & - \\
\hline b5 & 0.01 & - & - & - & - & - & - & - & - & - & - & - & - & - & - & - \\
\hline$b 6$ & - & - & - & - & - & 0.01 & 0.01 & - & 0.01 & - & - & - & - & - & - & - \\
\hline
\end{tabular}


Appendix 1 (continued)

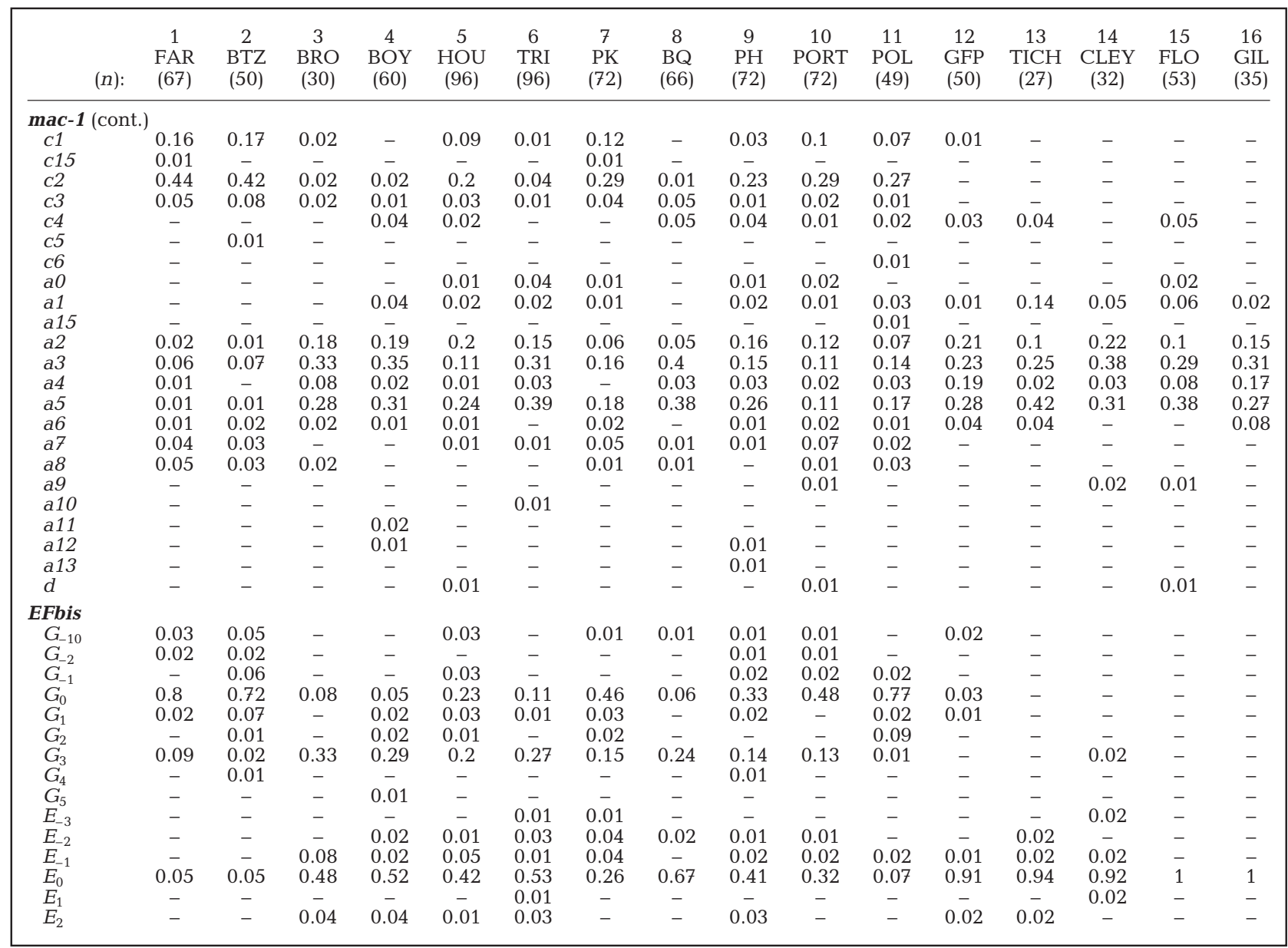

Appendix 2. Tests of homogeneity of genotypic frequencies between pairs of populations. NS: not significant; ${ }^{*} 0.01<\mathrm{p}<0.05$; ${ }^{* * *} \mathrm{p}<0.0001$. See Fig. 1 for sample names and locations

\begin{tabular}{|c|c|c|c|c|c|c|c|c|c|c|c|c|c|c|c|c|c|}
\hline & \multicolumn{2}{|c|}{ IPG } & \multicolumn{4}{|c|}{ BBE } & \multicolumn{2}{|c|}{ HP } & \multicolumn{2}{|c|}{ BG } & \multirow{2}{*}{$\begin{array}{c}\text { SWB } \\
11 \\
\text { POL }\end{array}$} & \multicolumn{5}{|c|}{ NSE } \\
\hline & & $\begin{array}{c}1 \\
\text { FAR } \\
\end{array}$ & $\begin{array}{c}2 \\
\text { BTZ }\end{array}$ & $\begin{array}{c}3 \\
\text { BRO } \\
\end{array}$ & $\begin{array}{c}4 \\
\text { BOY } \\
\end{array}$ & $\begin{array}{c}6 \\
\text { TRI } \\
\end{array}$ & $\begin{array}{c}8 \\
B Q\end{array}$ & $\begin{array}{c}5 \\
\mathrm{HOU} \\
\end{array}$ & $\begin{array}{c}9 \\
\mathrm{PH}\end{array}$ & $\begin{array}{c}7 \\
\text { PK }\end{array}$ & $\begin{array}{c}10 \\
\text { PORT }\end{array}$ & & $\begin{array}{c}12 \\
\text { GFP }\end{array}$ & $\begin{array}{c}13 \\
\text { TICH }\end{array}$ & $\begin{array}{c}14 \\
\text { CLEY }\end{array}$ & $\begin{array}{c}15 \\
\text { FLO }\end{array}$ & $\begin{array}{r}16 \\
\text { GIL } \\
\end{array}$ \\
\hline \multirow{2}{*}{ IPG } & 1 FAR & & NS & $* * *$ & $* * *$ & $* * *$ & $* * *$ & $* * *$ & $* * *$ & $* * *$ & $* * *$ & $* * *$ & $* * *$ & $* * *$ & $* * *$ & $* * *$ & $* * *$ \\
\hline & $2 \mathrm{BTZ}$ & & & $* * *$ & $* * *$ & $* * *$ & $* * *$ & $* * *$ & $* * *$ & $* * *$ & $* * *$ & $* * *$ & $* * *$ & $* * *$ & $* * *$ & $* * *$ & $* * *$ \\
\hline \multirow{4}{*}{$\mathrm{BBE}$} & $3 \mathrm{BRO}$ & & & & NS & NS & NS & $* * *$ & $* * *$ & $* * *$ & $* * *$ & $* * *$ & NS & NS & NS & NS & NS \\
\hline & $4 \mathrm{BOY}$ & & & & & NS & NS & $* * *$ & $* * *$ & $* * *$ & $* * *$ & $* * *$ & 痤 & NS & 原 & 原 & \% \\
\hline & $6 \mathrm{TRI}$ & & & & & & NS & $* * *$ & $* * *$ & $* * *$ & $* * *$ & $* * *$ & NS & NS & NS & \% & NS \\
\hline & $8 \mathrm{BQ}$ & & & & & & & $* * *$ & $* * *$ & $* * *$ & $* * *$ & $* * *$ & NS & NS & NS & 整 & NS \\
\hline \multirow{2}{*}{ HP } & $5 \mathrm{HOU}$ & & & & & & & & NS & $* * *$ & $* * *$ & $* * *$ & $* * *$ & $* * *$ & $* * *$ & $* * *$ & $* * *$ \\
\hline & $9 \mathrm{PH}$ & & & & & & & & & $* * *$ & $* * *$ & $* * *$ & $* * *$ & $* * *$ & $* * *$ & $* * *$ & $* * *$ \\
\hline \multirow{2}{*}{$\mathrm{BG}$} & $7 \mathrm{PK}$ & & & & & & & & & & NS & $* * *$ & $* * *$ & $* * *$ & $* * *$ & $* * *$ & $* * *$ \\
\hline & 10 PORT & & & & & & & & & & & $* * *$ & $* * *$ & $* * *$ & $* * *$ & $* * *$ & $* * *$ \\
\hline SWB & $11 \mathrm{POL}$ & & & & & & & & & & & & $* * *$ & $* * *$ & $* * *$ & $* * *$ & $* * *$ \\
\hline \multirow{4}{*}{ NSE } & 12 GFP & & & & & & & & & & & & & NS & NS & NS & NS \\
\hline & $13 \mathrm{TICH}$ & & & & & & & & & & & & & & NS & NS & NS \\
\hline & 14 CLEY & & & & & & & & & & & & & & & NS & NS \\
\hline & $\begin{array}{l}15 \text { FLO } \\
16 \text { GIL }\end{array}$ & & & & & & & & & & & & & & & & NS \\
\hline
\end{tabular}

IPG: Iberian Peninsula Mytilus galloprovincialis; BBE: Bay of Biscay M. edulis; HP: Hybrid populations; BG: Brittany M. galloprovincialis; SWB: South West Britain M. galloprovincialis; NSE: North Sea M. edulis 
Acknowledgements. We are very much indebted to L. Dupont for participating in laboratory analyses and to 3 anonymous referees for their constructive remarks. This research was funded in part by IFREMER URM 16.

\section{LITERATURE CITED}

Arnold WS, Marelli DC, Bert TM, Jones DS, Quitmyer IR (1991) Habitat-specific growth of hard clams Mercenaria mercenaria (L.) from the Indian River, Florida. J Exp Mar Biol Ecol 147:245-265

Arnold WS, Bert TM, Marelli DC, Cruz-Lopez H, Gill PA (1996) Genotype-specific growth of hard clams (genus Mercenaria) in a hybrid zone: variation among habitats. Mar Biol 125:129-139

Avise JC (1994) Molecular markers, natural history and evolution. Chapman \& Hall, New York

Barton NH (1979) The dynamics of hybrid zone. Heredity 43: 341-359

Barton NH (2000) Estimating multilocus linkage disequilibria. Heredity 84:373-389

Barton NH, Bengtsson BO (1986) The barrier to genetic exchange between hybridising populations. Heredity 56: 357-376

Beaumont AR, Abdul-Matin AKM, Seed R (1993) Early development, survival and growth in pure and hybrid larvae of Mytilus edulis and M. galloprovincialis. J Molluscan Stud 59:120-123

Belkhir K, Borsa P, Goudet J, Chikhi L, Bonhomme F (1996). GENETIX, logiciel sous WINDOWS ${ }^{\mathrm{TM}}$ pour la génétique des populations. Université de Montpellier 2, Montpellier

Benzécri JP (1982) L'analyse des données. Dunod, Paris

Bert TM, Arnold WS (1995) An empirical test of predictions of 2 competing models for the maintenance and fate of hybrid zones: both models are supported in a hard clam hybrid zone. Evolution 49:276-289

Bierne N, David P, Boudry P, Bonhomme F (2002) Assortative fertilization and selection at larval stage in the mussels Mytilus edulis and M. galloprovincialis. Evolution 56: 292-298

Bierne N, Bonhomme F, David P (in press a) Genetics at larval stage in marine bivalves. Recent Adv Mar Biotechnol 10

Bierne N, Borsa P, Daguin C, Jollivet D, Viard F, Bonhomme $F$, David P (in press b) Introgression patterns in the mosaic hybrid zone between Mytilus edulis and M. galloprovincialis. Mol Ecol

Bush GL (1975) Models of animal speciation. Annu Rev Ecol Syst 6:339-365

Coustau C, Renaud F, Delay B (1991) Genetic characterization of the hybridization between Mytilus edulis and M. galloprovincialis on the Atlantic coast of France. Mar Biol 111: 87-93

Daguin C, Borsa P (1999) Genetic characterisation of Mytilus galloprovincialis Lmk. in north west Africa using nuclear DNA markers. J Exp Mar Biol Ecol 235:55-65

Daguin C, Bonhomme F, Borsa P (2001) The zone of sympatry and hybridization of Mytilus edulis and M. galloprovincialis, as described by intron length polymorphism at locus mac-1. Heredity 86:342-354

Dawson KJ, Belkhir K (2001) A Bayesian approach to the identification of panmictic populations and the assignment of individuals. Genet Res 78:59-77

Desmarais E, Lanneluc I, Lagnel J (1998) Direct amplification of length polymorphism (DALP) or how to get and characterise new markers in many species. Nucleic Acid Res 26 : 1458-1465
Dobzhansky T (1940) Speciation as a stage in evolutionary divergence. Am Nat 74:312-321

Gardner JPA (1994) The structure and dynamics of naturally occurring hybrid Mytilus edulis and M. galloprovincialis (Bivalvia, Mollusca) populations: review and interpretation. Arch Hydrobiol 99(Suppl):37-71

Gardner JPA, Skibinski DOF (1988) Historical and sizedependent genetic variation in hybrid mussel populations. Heredity 61:93-105

Gardner JPA, Skibinski DOF (1990) Genotype-dependent fecundity and temporal variation of spawning in hybrid mussel populations. Mar Biol 105:153-162

Gardner JPA, Skibinski DOF (1991) Biological and physical factors influencing genotype-dependent mortality in hybrid mussel populations. Mar Ecol Prog Ser 71:235-243

Gardner JPA, Skibinski DOF, Bajdik CD (1993) Shell growth and viability differences between marine mussels Mytilus edulis (L.), M. galloprovincialis (Lmk.), and their hybrids from two sympatric populations in SW England. Biol Bull (Woods Hole) 185:405-416

Gosling EM, McGrath D (1990) Genetic variability in exposedshores mussels Mytilus spp. along an environmental gradient. Mar Biol 104:413-418

Gosling EM, Wilkins NP (1981) Ecological genetics of the mussel Mytilus edulis and M. galloprovicialis on Irish coasts. Mar Ecol Prog Ser 4:221-227

Hare MP, Karl SA, Avise JC (1996) Anonymous nuclear-DNA markers in the American oyster and their implications for the heterozygote deficiency phenomenon in marine bivalves. Mol Biol Evol 13:334-345

Hilbish TJ (2001) Genetics of hard clams, Mercenaria mercenaria. In: Kraeuter J, Castagna M (eds) Biology of the hard clam. Elsevier, New York

Hilbish TJ, Koehn RK (1985) Dominance in physiological phenotype and fitness at an enzyme locus. Science 229:52-54

Hilbish TJ, Bayne BL, Day A (1994) Genetics of the physiological differentiation within the marine mussel Mytilus. Evolution 48:267-286

Hilbish TJ, Carson EW, Plante JR, Weaver LA, Gilg MR (2002) Distribution of Mytilus edulis, M. galloprovincialis, and their hybrids in open-coast populations of mussels in southwestern England. Mar Biol 140:137-142

Inoue K, Waite JK, Matsuoka M, Odo S, Harayama S (1995) Interspecific variations in adhesive protein sequences of Mytilus edulis, M. galloprovincialis and M. trossulus. Biol Bull (Woods Hole) 189:370-375

Kirkpatrick M, Ravigné V (2002) Speciation by natural and sexual selection: models and experiments. Am Nat 159 (Suppl):S22-S35

Knowlton N, Weigt LA, Solorzano LA, Mills DK, Bermingham E (1993) Divergence in proteins, mitochondrial DNA, and reproductive compatibility across the isthmus of Panama. Science 260:1629-1632

Koehn RK, Newell RI, Immerman F (1980) Maintenance of an aminopeptidase allele frequency cline by natural selection. Proc Natl Acad Sci USA 77:5385-5389

Kruuk LE (1997) Barriers to gene flow: a Bombina (fire-bellied toad) hybrid zone and multilocus cline theory. $\mathrm{PhD}$ thesis, University of Edinburgh

Kruuk LE, Baird SJ, Gale KS, Barton NH (1999) A comparison of multilocus clines maintained by environmental adaptation or by selection against hybrids. Genetics 153: 1959-1971

Lazure P, Jegou A (1998) 3D modelling of seasonal evolution of Loire and Gironde plumes on Biscay Bay continental shelf. Oceanol Acta 21:165-177

Lazure P, Salomon J (1991) Etude par modèles mathéma- 
tiques de la circulation marine entre Quiberon et Noirmoutier. Oceanol Acta 11:93-99

Lemaire C, Allegrucci G, Naciri M, Bahri-Sfar L, Kara H, Bonhomme F (2000) Do discrepancies between microsatellite and allozyme variation reveal differential selection between sea and lagoon in the sea bass (Dicentrarchus labrax)? Mol Ecol 9:457-467

Levitan DR (1998) Sperm limitation, gamete competition and sexual selection in external fertilizers. In: Birkhead TR, Moller AP (eds) Sperm competition and sexual selection. Academic Press, New York, p 175-217

McGoldrick DJ, Hedgecock D, English LJ, Baoprasertkul P, Ward RD (2000) The transmission of microsatellite alleles in Australian and North American stocks of the pacific oyster (Crassostrea gigas): selection and null alleles. J Shellfish Res 19:779-788

Ohresser M, Borsa P, Delsert C (1997) Intron-length polymorphism at the actin-gene locus mac-1: a genetic marker for populations studies in the marine mussels Mytilus galloprovincialis and $M$. edulis. Mol Mar Biol Biotechol 6: $123-130$

Palumbi SR (1992) Marine speciation on a small planet. Trends Ecol Evol 7:114-118

Palumbi SR (1994) Genetic divergence, reproductive isolation, and marine speciation. Annu Rev Ecol Syst 25: $547-572$

Quesada H, Wenne R, Skibinski DOF (1995) Differential introgression of mitochondrial DNA across species boundaries within the marine mussel genus Mytilus. Proc R Soc Lond Ser B 262:51-56

Quesada H, Gallagher C, Skibinski DAG, Skibinski DOF (1998) Patterns of polymorphism and gene flow of genderassociated mitochondrial DNA lineages in European mussel populations. Mol Ecol 7:1041-1051

Rawson PD, Hilbish TJ (1998) Asymmetric introgression of mitochondrial DNA among European populations of blue mussels (Mytilus spp.). Evolution 52:100-108

Rawson PD, Joyner KL, Meetze K, Hilbish TJ (1996) Evidence for intragenic recombination within a novel genetic marker that distinguishes mussels in the Mytilus edulis species complex. Heredity 77:599-607

Raymond M, Rousset F (1995) GENEPOP (ver. 1.2): A population genetics software for exact test and ecumenicism. J Hered 86:248-249

Rice WR (1984) Disruptive selection on habitat preference and the evolution of reproductive isolation - a simulation study. Evolution 38:1251-1260

Rice WR (1987) Speciation via habitat specialization: the evolution of reproductive isolation as a correlated character. Evol Ecol 1:301-314

Editorial responsibility: Otto Kinne (Editor), Oldendorf/Luhe, Germany
Rieseberg LH, Whitton J, Gardner K (1999) Hybrid zones and the genetic architecture of a barrier to gene flow between 2 sunflower species. Genetics 152:713-727

Riginos C, Sukhdeo K, Cunningham CW (2002) Evidence for selection at multiple allozyme loci across a mussel hybrid zone. Mol Biol Evol 19:347-351

Schmidt PS, Rand DM (2001) Adaptive maintenance of genetic polymorphism in an intertidal barnacle: habitatand life-stage-specific survivorship of MPI genotypes. Evolution 55:1336-1344

Schmidt PS, Bertness MD, Rand DM (2000) Environmental heterogeneity and balancing selection in the acorn barnacle Semibalanus balanoides. Proc R Soc Lond Ser B 267: 379-384

Secor CL, Day AJ, Hilbish TJ (2001) Factors influencing differential mortality within a marine mussel (Mytilus spp.) hybrid population in southwestern England: reproductive effort and parasitism. Mar Biol 138:731-739

Seed R (1971) A physiological and biochemical approach to the taxonomy of Mytilus edulis L. and M. galloprovincialis Lmk. from S.W. England. Cah Biol Mar 12:291-322

Skibinski DOF (1983) Natural selection in hybrid mussel populations. In: Rollinson O (ed) Protein polymorphism: adaptative and taxonomic significance. Systematics Association Special Volume No. 24. Academic Press, New York, p 283-299

Skibinski DOF, Roderick EE (1991) Evidence of selective mortality in favour of the Mytilus galloprovincialis (Lmk.) phenotype in British mussel populations. Biol J Linn Soc 42:351-366

Skibinski DOF, Beardmore JA, Cross TF (1983) Aspects of the population genetics of Mytilus (Mytilidae; Mollusca) in the British Isles. Biol J Linn Soc 19:137-183

Slatkin M (1973) Gene flow and selection in a cline. Genetics 75:733-756

Turner JRG (1967) Why does the genotype not congeal? Evolution 21:645-656

Viard F, Delay B, Coustau C, Renaud F (1994) Evolution of the genetic structure of bivalve cohorts at hybridization sites of the Mytilus edulis-M. galloprovincialis complex. Mar Biol 119:535-539

Wihelm RJ, Hilbish TJ (1998) Assessment of natural selection in a hybrid population of mussels: evaluation of exogenous vs. endogenous selection models. Mar Biol 131:505-514

Willis GL, Skibinski DOF (1992) Variation in strength of attachment to the substrate explains differential mortality in hybrid mussel (Mytilus galloprovincialis and M. edulis) populations. Mar Biol 112:403-408

Wolfram S (1996) The mathematica book, 3 edn. Wolfram Media/Cambridge University Press, Cambridge

Submitted: February 20, 2002; Accepted: September 29, 2002 Proofs received from author(s): November 28, 2002 